Eckhard von Raab-Straube, with editors and authors of the Euro+Med PlantBase

\title{
From Flora Europaea and Med-Checklist to Euro+Med PlantBase: the never-ending task for a happy Sisyphos
}

\author{
Raab-Straube von, E. with the editors and authors of the Euro+Med PlantBase: From Flora \\ Europaea and Med-Checklist to Euro+Med PlantBase: the never-ending task for a happy \\ Sisyphos. - Bocc. 28: 271-272. 2019. - ISSN: 1120-4060 printed, 2280-3882 online. \\ Key words: Mediterranean flora, European flora, databasing.
}

As of $1^{\text {st }}$ of February 2018, 18 years after the project has begun, the Euro+Med PlantBase $(\mathrm{E}+\mathrm{M})$ has finally reached full coverage of vascular plant taxa. $\mathrm{E}+\mathrm{M}$ now provides free access to a complete checklist of the European and the Mediterranean Flora, including also the Macaronesian Islands and the Caucasus. E+M is the most comprehensive taxonomic information system on plant biodiversity of the region, designed as a dynamic, permanently updated and critically evaluated on-line checklist. However, due to the limited number of active contributors, data quality is still heterogeneous. The bulk of the data originates from the merge of Flora Europaea, Med-Checklist, the Flora of Macaronesia plus ongoing additions from more than one hundred recent standard floras, checklists, taxonomic monographs and floristic publications. Still, ca. $15 \%$ of the taxa had to be taken from external sources, namely from the World Checklist of Selected Plant Families, Kew, and from the International Legume Database and Information Service (ILDIS) for the Fabaceae. Work is currently in progress to replace those external data with original, amended and updated $\mathrm{E}+\mathrm{M}$ data. $\mathrm{E}+\mathrm{M}$ now contains 224 families with 2409 genera and a total of 44437 taxa (32760 species and 11677 subspecies), including those genera with very large numbers of apomictic microspecies. The database provides 47620 accepted names and 94310 synonyms with standardized nomenclatural citations, misapplied names, orthographic variants, 147804 common names in 53 different languages, 375810 source-referenced distribution records for 46644 taxa, and literature-based distribution maps. Suprageneric classification has been updated and now largely follows the APG IV system. The forthcoming migration of the database to the Common Data Model will allow for easier editing, immediate on-line 
272 Raab-Straube von \& al.: From Flora Europaea and Med-Checklist to Euro+Med...

publication of additions and corrections, easier connection with other data resources, and direct publications of selected datasets for defined regions or taxonomic groups.

Address of the authors:

Eckhard von Raab-Straube, with editors and authors of the Euro+Med PlantBase,

Freie Universität Berlin, Botanic Garden and Botanical Museum Berlin, Königin-Luise-Str. 6-8, 14195 Berlin, Germany. E-mail: E.RaabStraube@bgbm.org 